\title{
Pengembangan Media Pembelajaran Berbasis Powerpoint Padu Musik Untuk Meningkatkan Hasil Belajar IPS Siswa Kelas 5 SDN 105326 Bangun Rejo
}

\author{
Muhammad Aldi', Beta Rapita Silalahi' ${ }^{2}$ \\ 1,2Universitas Muslim Nusantara Al-Washliyah
}

Corresponding Author: $\otimes$ muhammadaldi9910@gmail.com

\begin{tabular}{ll}
\hline & \multicolumn{1}{c}{ ABSTRACT } \\
\hline & The aim of the researcher is to describe the Development of PowerPoint- \\
Based Learning Media with Music to Improve Social Studies Learning \\
Outcomes for 5th Graders at SDN 105326 Bangun Rejo. This research is a \\
type of research with a development model or Research and Development \\
(R\&D) with a research product, namely PowerPoint-based learning \\
media. Based on the results of inferential statistical analysis using the t \\
test formula, it can be seen that the value is 43,640. With a frequency (dk) \\
of $31-1=30$ at a significance level of 5\%, it is obtained = 1,571. Therefore \\
$>$ at a significance level of 0.05, the null hypothesis is rejected and the \\
alternative hypothesis is accepted, and on the T-test, the Sig value is 0.000, \\
which means that there is an influence in using Powerpoint-Based \\
Learning Media with Music on the student learning outcomes in social \\
studies subjects, especially on the subject of regional culture in Indonesia \\
class V SDN 105326 Bangun Rejo. The results of the analysis above which \\
show the influence of Powerpoint-Based Learning Media Unified Music \\
are in line with the results of observations made, besides Cronbach's \\
Alpha is obtained 0.820 which is Cronbach's Alpha > 0.7, then the data of \\
Media-Based Learning Powerpoint Padu Musik is considered reliable or \\
valid.
\end{tabular}

\section{PENDAHULUAN}

Berdasarkan Permendikbud No. 22 tahun 2016 bahwa proses pembelajaran pada satuan pendidikan diselenggarakan secara interaktif, inspiratif, menyenangkan, menantang, memotivasi peserta didik untuk berpartisipasi aktif serta memberikan ruang yang cukup bagi prakarsa, kreativitas, dan kemandirian sesuai bakat, minat, dan perkembangan fisik serta psikologis peserta didik.

Permendikbud Nomor 57 Tahun 2014 mengenai pedoman pembelajaran tematik, menyatakan bahwa Ilmu Pengetahuan Sosial (IPS) adalah mata pelajaran yang mempelajari tentang kehidupan manusia dalam berbagai ruang 
Ability : Journal of Education and Social Analysis

Volume 2, Issue 4, Oktober 2021

Page : 123-134

dan waktu serta berbagai aktivitas kehidupannya. Muatan pelajaran IPS ini bertujuan untuk menghasilkkan warga negara yang religius, jujur, demokratif, kreatif, dan kritis, senang membaca, memiliki kemampuan belajar, rasa ingin tahu, peduli dengan lingkungan sosial dan fisik, berkontribusi terhadap pengembangan kehidupan sosial dan budaya, serta berkomunikasi secara produktif.

Menurut Sumaatmadja (dalam Hidayati, 2011: 24) menyatakan bahwa melalui Ilmu Pengetahuan Sosial (IPS) siswa dapat berinteraksi di lingkungan keluarga, sekolah maupun di lingkungan masyarakat. Karena pendidikan ilmu pengetahuan sosial memiliki tujuan untuk "membina anak didik menjadi warga Negara yang baik, yang memiliki pengetahuan keterampilan dan kepedulian sosial yang berguna bagi dirinya serta bagi masyarakat dan negara".

Menurut Kurniyati (2016: 1) IPS merupakan salah satu mata pelajaran yang wajib dipelajari di Sekolah Dasar (SD). Oleh karena itu sangatlah penting mengajarkan pendidikan Ilmu Pengetahuan Sosial.

Melalui mata pelajaran IPS, siswa dapat diarahkan untuk mengembangkan pengetahuan serta pemahaman konsep yang bermanfaat bagi kehidupan sehari-hari. Oleh karena itulah, sudah seharusnya guru mampu menciptakan pembelajaran yang efektif dan menyenangkan agar dapat menunjang tercapainya tujuan pembelajaran yang telah dirumuskan.

Berdasarkan hasil observasi dan wawancara yang dilakukan pada tanggal 7 Januari 2021 di SDN 105326 Bangun Rejo, peneliti menemukan suatu permasalahan bahwa pemanfaatan media pembelajaran di kelas belum optimal. Guru hanya menggunakan buku guru dan buku siswa dalam pembelajaran IPS di kelas, sedangkan cakupan materi IPS sangat luas dan alokasi waktu yang sedikit. Beberapa siswa merasa tidak tertarik dan kurang aktif dalam pembelajaran yang berlangsung, sehingga hal ini berdampak pada menurunnya hasil belajar IPS siswa kelas V di SDN 105326. Melihat kondisi tersebut, salah satu upaya yang dapat dilakukan adalah memberikan variasi terhadap berlangsungnya proses belajar mengajar dengan menggunakan media pembelajaran yang sesuai agar dapat menarik perhatian dan meningkatkan hasil belajar siswa.

Dalam pembelajaran IPS, media pembelajaran yang bervariasi sangatlah dibutuhkan. Terlebih pada zaman modernisasi seperti saat ini, penggunaan media pembelajaran berbasis teknologi sudah menjadi suatu kebutuhan di sekolah. Tidak dipungkiri lagi bahwa penggunaan media pembelajaran merupakan salah satu komponen penting di dalam proses belajar mengajar di sekolah. Penggunaan media dipandang penting karena dapat membantu guru 
Ability : Journal of Education and Social Analysis

Volume 2, Issue 4, Oktober 2021

Page : 123-134

dalam mencapai suatu tujuan pembelajaran dalam pendidikan. Oleh karena itu, penyiapan media pembelajaran menjadi salah satu tanggung jawab pengajar.

Menurut Azhar Arsyad (2011: 2) perkembangan ilmu pengetahuan dan teknologi semakin mendorong upaya-upaya pembaharuan dalam pemanfaatan hasil-hasil teknologi dalam proses belajar. Untuk itu guru harus memiliki pengetahuan dan pemahaman yang cukup tentang media pembelajaran, yang meliputi : (1) Media sebagai alat komunikasi guna lebih mengefektifkan proses belajar mengajar; (2) Fungsi media dalam rangka mencapai tujuan pendidikan; (3) Seluk-beluk proses belajar; (4) Hubungan antara metode mengajar dan media pendidikan; (5) Nilai atau manfaat media pendidikan dalam pengajaran; (6) Pemilihan dan penggunaan media pendidikan; (7) Berbagai jenis alat dan tehnik media pendidikan; (8) Media pendidikan dalam setiap mata pelajaran; (9) Usaha inovasi dalam media pendidikan.

Menurut Nana Sudjana dan Ahmad Rivai, (2013: 2) ada beberapa alasan media pengajaran dapat mempertinggi proses belajar siswa, diantaranya: (1) pengajaran akan lebih menarik perhatian siswa sehingga dapat menumbuhkan motivasi belajar; (2) bahan pengajaran akan lebih jelas maknanya sehingga akan lebih dipahami oleh para siswa dan memungkinkan siswa menguasai tujuan pengajaran lebih baik, (3) metode mengajar akan lebih bervariasi, dan siswa lebih banyak melakukan kegiatan belajar sebab tidak hanya mendengarkan uraian guru tetapi juga aktivitas lain seperti mengamati, melakukan, mendemonstrasikan dan lain-lain.

Senada dengan pendapat di atas Oemar Hamalik, (dalam Azhar Arsyad, 2011: 15) mengemukakan bahwa pemakaian media pembelajaran dalam proses belajar mengajar dapat membangkitkan keinginan dan minat yang baru, membangkitkan motivasi dan rangsangan kegiatan belajar, dan bahkan membawa pengaruh-pengaruh psikologis terhadap siswa. Penggunaan media pembelajaran pada tahap orientasi pembelajaran akan sangat membantu efektivitas proses pembelajaran dan penyampaian pesan atau isi pelajaran pada saat itu.

Dalam penelitian ini, peneliti akan mengembangkan media pembelajaran berbasis PowerPoint padu musik sebagai upaya dalam meningkatkan hasil belajar IPS siswa.

Lebih lanjut, Widya Wijayanti, dkk (2019: 77) menyatakan bahwa pembelajaran menggunakan media PowerPoint dirancang untuk pembelajaran interaktif, di mana dalam media presentasi PowerPoint dirancang dan dilengkapi dengan alat pengontrol yang dapat dioperasikan oleh pengguna sehingga penggunaan dapat memilih apa yang dikehendaki untuk petunjuk penggunaan, materi, dan soal latihan. 
Ability : Journal of Education and Social Analysis

Volume 2, Issue 4, Oktober 2021

Page : 123-134

Penggunaan media powerpoint yang secara karakteristiknya bersifat multimedia, yang tidak hanya dapat menampilkan teks saja, tetapi dapat di padukan dengan unsur gambar, video, animasi dan musik dalam penyajian persentasi kepada siswa. Penggunaan media powerpoint yang dipadukan dengan musik merupakan salah satu upaya dalam mengakomodasikan gaya belajar siswa secara visual dan audio. Don Campbell, dalam bukunya yang berujul "The Mozart Effect" banyak mengungkapkan hasil penelitian berkaitan dengan pengaruh musik terhadap perkembangan individu dan memberikan banyak efek menguntungkan dari jenis musik tertentu. Dalam buku tersebut dikemukakan keuntungan-keuntungan yang didapatkan dari musik yang dimanfaatkan dalam pembelajaran, di antaranya adalah meningkatkan nilai tes, mempercepat waktu pembelajaran, menenangkan anakanak dan orang dewasa yang hiperaktif, mengurangi tingkat kesalahan, meningkatkan kreativitas dan kejernihan dalam berpikir, menyembuhkan tubuh lebih cepat, mengintegrasikan kedua belah otak untuk belajar lebih efisien. Dengan kata lain, musik mengaktifkan seluruh bagian otak dan membuat merasa lebih giat. Hasil penelitian ini begitu menarik perhatian sehingga buku The Mozart Effect karangan Don Campbell (1997), begitu monumental .

Berdasarkan latar belakang tersebut, maka peneliti melakukan penelitian dengan judul “Pengembangan Media Pembelajaran Berbasis PowerPoint Padu Musik Untuk Meningkatkan Hasil Belajar IPS Siswa Kelas 5 SDN 105326 Bangun Rejo".

\section{METODE PENELITIAN}

Penelitian ini merupakan jenis penelitian dengan model pengembangan atau Research and Development (R\&D) dengan produk penelitian yaitu media pembelajaran berbasis PowerPoint. Menurut Sugiyono (2016: 407), metode penelitian dan pengembangan atau dalam Bahasa Inggrisnya Research and Development adalah metode penelitian yang digunakan untuk menghasilkan produk tertentu, dan menguji kefektifan produk tersebut. Sedangkan menurut Borg and Gall (dalam Sugiyono, 2016) menyatakan bahwa penelitian dan pengembangan (research and development) merupakan metode penelitian yang digunakan untuk mengembangkan atau memvalidasi produk-produk yang digunakan dalam pendidikan dan pembelajaran.

Penelitian pengembangan yang dilakukan peneliti bertujuan untuk menghasilkan produk yang efektif guna membantu siswa dalam memahami mata pelajaran IPS melalui media PowerPoint. Penerapan prosedur pengembangan dalam penelitian ini disederhanakan dan 
disesuaikan dengan kebutuhan peneliti, juga keterbatasan waktu dan dana yang dimiliki oleh peneliti. Berikut langkah-langkah dalam penelitian ini adalah sebagai berikut:

1) Tahap Pengumpulan Data

Tahap pengumpulan data dilakukan untuk mendapatkan informasi yang jelas terkait produk yang akan dikembangkan. Informasi mengenai kebuthan siswa dan guru dalam pembelajaran sangat dibutuhkan guna keberhasilan suatu produk yang dikembangkan. Hal ini sebagai bahan untuk perencanaan pengembangan produk berupa media pembelajaran PowerPoint yang diharapkan dapat mengatasi masalah pada pembelajaran IPS di kelas V SDN 105326 Bangun Rejo.

2) Desain Produk Awal

Pada tahap ini, konsep yang telah dirancang kemudian diwujudkan dalam bentuk produk berupa media pembelajaran PowerPoint. Peneliti berusaha mendesai produk sesuai dengan kebutuhan siswa dan guru, serta kurikulum yang berlaku di SDN 105326

Bangun Rejo.

3) Validasi Desain

Merupakan proses kegiatan untuk menilai apakah rancangan produk, dalam hal ini metode mengajar baru secara rasional akan lebih efektif dari yang lama atau tidak. Dikatakan secara rasional, karena validasi disini masih bersifat penilaian berdasarkan pemikiran rasional, belum fakta lapangan.

4) Revisi Produk

Setelah desain produk divalidasi melalui diskusi dengan pakar dan para ahli lainnya, maka akan dapat diketahui kelemahannya. Kelemahan tersebut selanjutnya dicoba untuk dikurangi dengan cara memperbaiki desain. Yang bertugas memperbaiki desain adalah peneliti yang mau menghasilkan produk tersebut.

5) Uji Coba Produk

Setelah produk selesai dikembangkan, maka langkah selanjutnya adalah melakukan uji coba produk pengembangan media pembelajaran berbasis PowerPoint. Uji coba produk ditujukan kepada siswa kelas $\mathrm{V}$ SDN 105326 Bangun Rejo. Hasil yang diperoleh dari uji coba produk ini adalah berupa tanggapan siswa dan skor hasil belajar siswa setelah menggunakan media pembelajaran PowerPoint. 
Ability : Journal of Education and Social Analysis

Volume 2, Issue 4, Oktober 2021

Page : 123-134

6) Produk Akhir

Tahap ini adalah tahap penyempurnaan produk setelah dilakukan revisi atau perbaikan. Berikut untuk lebih jelasnya dapat dilihat dalam bagan prosedur pengembangan di bawah ini.

\section{HASIL PENELITIAN DAN PEMBAHASAN}

\section{Media Pembelajaran Berbasis Powerpoint Padu Musik}

Alasan peneliti mengembangkan media Media Pembelajaran Berbasis Powerpoint Padu Musik adalah agar media tersebut dapat membantu menyajikan suatu kejadian atau peristiwa secara kronologis dengan menghadirkan orang, benda, dan latar. Kronologi atau urutan kejadian peristiwa tersebut dapat memudahkan siswa untuk menuangkan idenya dalam kegiatan bercerita sehingga masuk dalam aspek berbicara siswa.

Berikut tampilan beberapa gambar pada Media Pembelajaran Berbasis Powerpoint Padu Musik:

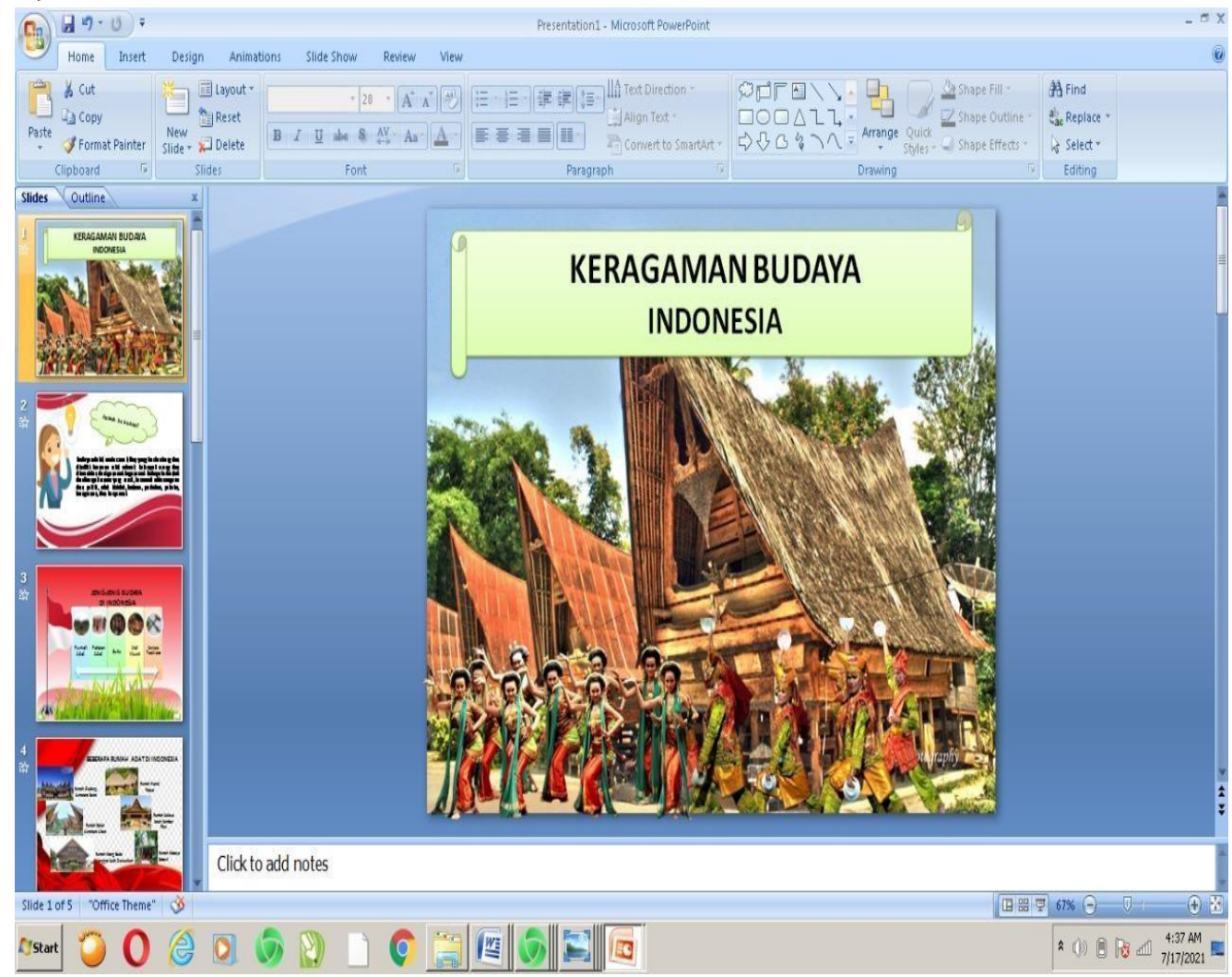


Ability : Journal of Education and Social Analysis

Volume 2, Issue 4, Oktober 2021

Page : 123-134
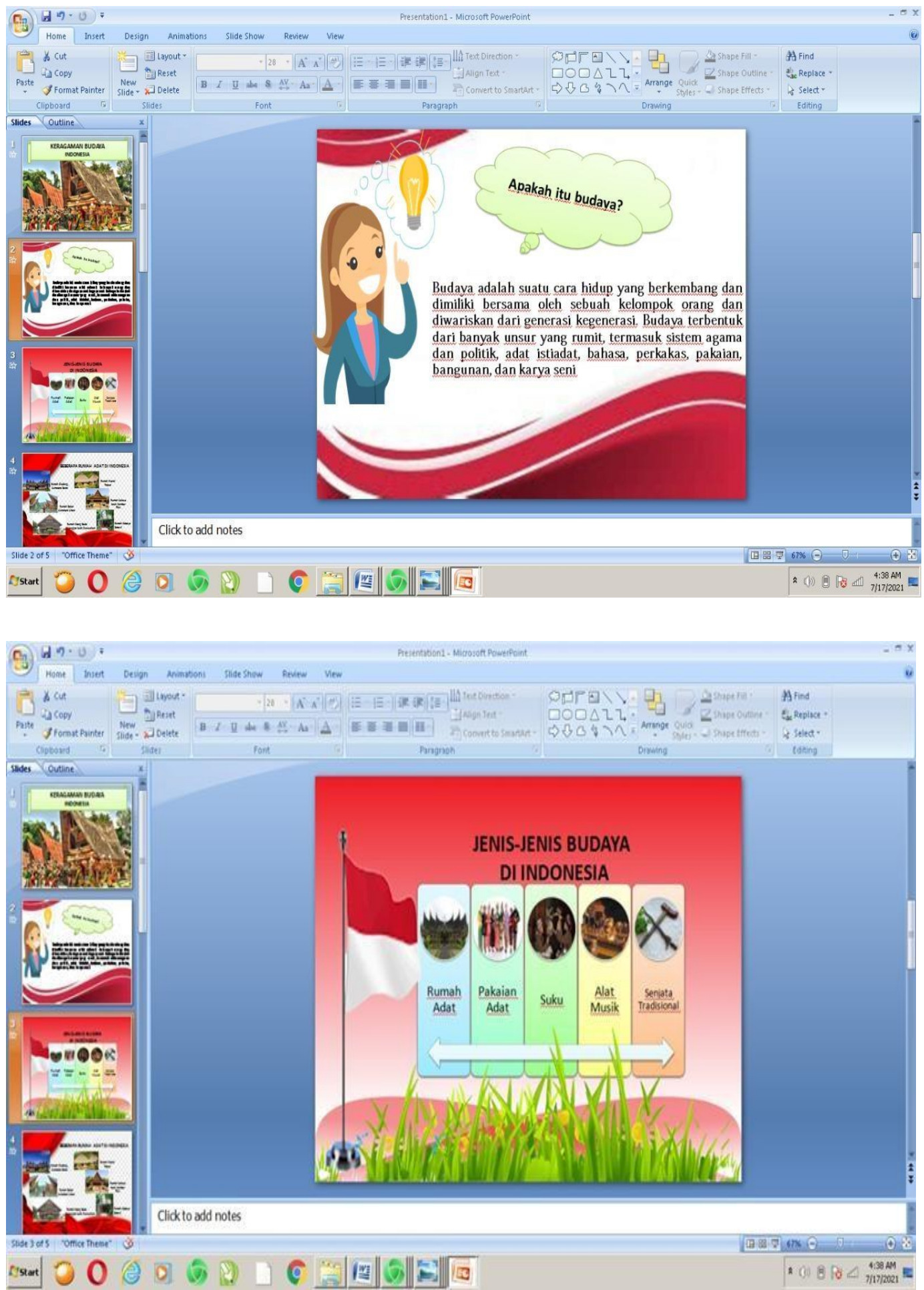

\section{Gambar 1. Tampilan sekilas Media Pembelajaran Berbasis Powerpoint Padu Musik}

Dalam pembuatan media pembelajaran ini, dibutuhkan proses yang tidak sebentar. Peneliti membutuhkan sebuah software pada komputer atau laptop yang dapat membuat, mendesain, mengedit, serta menggabungkan gambar 
yang seperti diinginkan. Software yang saat ini sering digunakan adalah Power Point . Peneliti memilih menggunakan software tersebut karena masing-masing software memiliki kelebihan dan kekurangan masing-masing yang dapat saling melengkapi satu sama lain serta mudah juga dalam penggunaannya.

\section{Alur Cerita Media Pembelajaran Berbasis Powerpoint Padu Musik}

Alur cerita pada Media Pembelajaran Berbasis Powerpoint Padu Musik dibuat sesederhana mungkin dengan didasarkan pada kompetensi dasar yang ada pada silabus. Kompetensi dasar yang dimaksud adalah budaya daerah di Indonesia. Media Pembelajaran Berbasis Powerpoint Padu Musik merupakan media pembelajaran termasuk media yang jarang digunakan oleh guru untuk meningkatkan hasil belajar siswa.

Hal ini sesuai dengan hasil penelitian sebelumnya yang mengungkapkan bahwa hasil belajar kelas eksperimen yang menggunakan Media Pembelajaran Berbasis Powerpoint Padu Musik dapat membantu siswa dalam mempelajarai tentang kebudayaan daerah yang ada di Indonesia. Produk yang dikembangkan adalah system power point dan meliputi pengembangan cara membuat, dan aturan penggunaan media itu tersebut.

Pembuatan desain Media Pembelajaran Berbasis Powerpoint Padu Musik memperhatikan permasalahan, potensi dan kebutuhan siswa. Media Pembelajaran Berbasis Powerpoint Padu Musik dikembangkan menjadi beberapa slide yang unik. Hal tersebut bertujuan agar siswa mempunyai rasa ketertaikkan untuk belajar dengan tampilan unik dari beberapa slide tersebut dan siswa lebih semangat dan tidak merasa bosan ketika belajar, peneliti memperhatikan prinsip pengembangan media visual berupa kesederhanaan, keterpaduan, penekanan, dan keseimbangan sehingga menarik untuk digunakan.

\section{Pembahasan}

Berdasarkan hasil pengembangan dapat diketahui bahwa produk Media Pembelajaran Berbasis Powerpoint Padu Musik untuk mata pelajaran IPS dikembangkan sesuai dengan model ADDIE, yakni Analyze, Design, Development, Implementation, dan Evaluation. Proses pengembangan media pembelajaran ini telah melalui beberapa tahap pengembangan dan validasi dari para ahli sehingga diperoleh produk akhir yang layak untuk diterapkan dalam proses pembelajaran.

Pada bagian ini akan diuraikan hasil yang ditemukan dalam penelitian. Hasil yang dimaksudkan yaitu kesimpulan yang diambil berdasarkan data yang terkumpul dan analisis data yang telah dilakukan. Berdasarkan hasil 
Ability : Journal of Education and Social Analysis

Volume 2, Issue 4, Oktober 2021

Page : 123-134

angket, nilai rata-rata hasil belajar siswa 83,06\% dengan kategori yakni kategori baik, dan terlihat dengan menggunakan Media Pembelajaran Berbasis Powerpoint Padu Musik materi budaya daerah di Indonesia siswa dapat mengerti dan semangat untuk menghafal beberapa inti dari kebudayaan Indonesia melalui Media Pembelajaran Berbasis Powerpoint Padu Musik tersebut, terlihat dari hasil nilai maksimum dan minimum di setiap item pada angket yang berarti menunjukkan media tersebut sangat bermanfaat dan mendukung mata pelajaran demi meningkatkan mutu pembelajaran disetiap materinya.

Berdasarkan hasil analisis statistik inferensial dengan menggunakan rumus uji $t$, dapat diketahui bahwa nilai sebesar 43.640. Dengan frekuensi (dk) sebesar $31-1=30$ pada taraf signifikansi $5 \%$ diperoleh $=1,571$. Oleh karena itu $>$ pada taraf signifikansi 0,05, maka hipotesis nol ( ) ditolak dan hipotesis alternative ( ) diterima,dan pada T-test diperoleh nilai Sig adalah sebesar 0,000 yang berarti bahwa ada pengaruh dalam menggunakan melalui Media Pembelajaran Berbasis Powerpoint Padu Musik terhadap hasil belajar siswa pada mata pelajaran IPS

Khususnya pada materi Budaya daerah di Indonesia kelas V SDN 105326 Bangun Rejo, yang beralamatkan Jalan Limau Mungkur Dusun VII Bangun Rejo, Bangun Rejo, Kec. Tanjung Morawa, Kab. Deli Serdang Prov. Sumatera Utara.

Hasil analisis di atas yang menunjukkan adanya pengaruh Media Pembelajaran Berbasis Powerpoint Padu Musik sejalan dengan hasil observasi yang dilakukan, selain itu Cronbach's Alpha di peroleh 0,820 yang dimana Cronbach's Alpha > 0,7, maka data Media Pembelajaran Berbasis Powerpoint Padu Musik diangkap reliable atau valid.

Berdasarkan hasil observasi terdapat perubahan pada siswa yaitu pada awal kegiatan pembelajaran ada beberapa siswa yang melakukan kegiatan lain atau bersikap cuek selama pembelajaran berlangsung. Berdasarkan hasil analisis statistik deskriptif dan statistik inferensial yang diperoleh serta hasil observasi yang telah dilakukan, dapat disimpulkan bahwa ada pengaruh dalam penggunaan Media Pembelajaran Berbasis Powerpoint Padu Musik terhadap hasil belajar matapelajaran IPS siswa kelas V SDN 105326 Bangun Rejo.

Berdasarkan data dan deskripsi diatas, dapat disimpulkan bahwa produk Media Pembelajaran Berbasis Powerpoint Padu Musik efektif digunakan dalam proses pembelajaran. Hal ini dapat dilihat dengan adanya peningkatan hasil belajar siswa terhadap pembelajaran budaya daerah di Indonesia siswa setelah menggunakan Media Pembelajaran Berbasis Powerpoint Padu Musik karena dengan Media Pembelajaran Berbasis Powerpoint Padu Musik siswa belajar 
Ability : Journal of Education and Social Analysis

Volume 2, Issue 4, Oktober 2021

Page : 123-134

tidak monoton dan di rangsang untuk berfikir kreatif dan inovatif untuk mencari tau isi hasil pemahaman mereka terhadap media tersebut dan membuat siswa berani belajar mata pelajaran yang dianggap ulit dengan berpendapat sesuai penalaran masing-masing siswa, selain itu dengan Media Pembelajaran Berbasis Powerpoint Padu Musik siswa terlihat tertarik dan semangat untuk belajar mata pelajaran tersebut, sehingga memudahkan guru untuk menjelaskan tentang materi yang telah di sampaikan.

\section{KESIMPULAN}

Berdasarkan penelitian yang telah dilakukan, berkaitan dengan rumusan masalah dan tujuan penelitian maka dapat disimpulkan sebagai berikut:

1. Model pengembangan yang digunakan adalah model pengembangan ADDIE. Tahapannya, antara lain (1) Analysis, yakni dengan melakukan observasi awal untuk mencari potensi masalah yang kemudian dicari sebuah solusi untuk mengatasinya. (2) Design, yakni membuat desain media pembelajaran berdasarkan silabus dan RPP yang ada. (3) Development, yakni tahapan produksi dengan berpedoman pada rancangan tampilan yang telah dibuat. (4) Implementation, yakni tahap uji coba produk, tahap validasi ahli, dan tahap penerapan langsung dalam pembelajaran. (5) Evaluation, yakni melakukan peniliaian berdasarkan angket yang telah disediakan untuk mengetahui apakah media multiplys card pembelajaran operasi perkalian bilangan bulat dapat meningkatkan hasil belajar siswa.

2. Berdasarkan hasil analisis statistik inferensial dengan menggunakan rumus uji $t$, dapat diketahui bahwa nilai sebesar 43.640. Dengan frekuensi $(\mathrm{dk})$ sebesar $31-1=30$ pada taraf signifikansi $5 \%$ diperoleh $=$ 1,571. Oleh karena itu > pada taraf signifikansi 0,05, maka hipotesis nol ( ) ditolak dan hipotesis alternative ( ) diterima,dan pada T-test diperoleh nilai Sig adalah sebesar 0,000 yang berarti bahwa ada pengaruh dalam menggunakan melalui Media Pembelajaran Berbasis Powerpoint Padu Musik terhadap

hasil belajar siswa pada mata pelajaran IPS Khususnya pada materi Budaya daerah di Indonesia kelas V SDN 105326 Bangun Rejo

3. Hasil analisis di atas yang menunjukkan adanya pengaruh Media Pembelajaran Berbasis Powerpoint Padu Musik sejalan dengan hasil observasi yang dilakukan, selain itu Cronbach's Alpha di peroleh 0,820 yang dimana Cronbach's Alpha > 0,7, maka data Media Pembelajaran Berbasis Powerpoint Padu Musik diangkap reliable atau valid. 
Ability : Journal of Education and Social Analysis

Volume 2, Issue 4, Oktober 2021

Page : 123-134

\section{REFERENCES}

Apidah, Nur., dkk. 2019. Pendidikan IPS dalam Kurikulum 2013. PGMI Fakultas Tarbiah dan Ilmu Keguruan: IAIN Padang Sidimpuan.

Azhar Arsyad. 2011. Media Pembelajaran. Jakarta: Raja Grafindo.

Daryanto. 2016. Media Pembelajaran. Yogyakarta: Gava Media.

Erhans Anggawirya. 2011. Microsoft Powerpoint. Jakarta: PT. Ercontara Rajawali.

Fanny, Arif Mahya dan Siti Partini Suardiman. 2013. Pengembangan Multimedia Interaktif untuk Mata Pelajaran Ilmu Pengetahuan Sosial (IPS)

Sekolah Dasar Kelas V. Jurnal Prima Edukasia. Volume 1 (1) : 1-9

Hamdani. 2011. Strategi Belajar Mengajar. Bandung: Pustaka Setia.

Hidayati., Mujinem., \& Senen, Anwar. 2011. Pengembangan Pendidikan IPS SD. Jakarta:

Direktorat Jenderal Pendidikan Tinggi Departemen Pendidikan Nasional.

Istiningsih. 2012. Pemanfaatan TIK dalam Pembelajaran. Yogyakarta: Media Kreatif.

Kurniyati Dwi. 2016. Peningkatan Hasil Belajar IPS dengan Menerapkan Model Pembelajaran

Quantum Teaching di SD N Balong. Jurnal Pendidikan Guru Sekolah Dasar Edisi 4. Mutmainah. 2018. Penggunaan Media Pembelajaran Powerpoint Untuk Meningkatkan Motivasi Dan Hasil Belajar Siswa Sekolah Dasar. Jurnal Teknologi Pendidikan dan Pembelajaran, Tahun 5, Nomor 2 November 2018.

Nunuk Suryani., Pengembangan Media Pembelajaran Berbasis IT, Workshop Nasional

Pascasarjana Program Studi Teknologi Pendidikan Universitas Sebelas Maret, 2015.

Permendikbud No. 22 tahun 2016 tentang Proses Pembelajaran.

Permendikbud Nomor 57 Tahun 2014 tentang Pedoman Pembelajaran Tematik.

Purwanto, N. 2013. Prinsip-Prinsip dan Teknik Evaluasi Pengajaran. Bandung: PT. Remaja Rosdakarya.

Rifka, Ayu. 2019. Penggunaan Media Microsoft Power Point untuk Meningkatkan Pemahaman Konsep pembelajaran IPS Peserta Didik Kelas IV Sa'adatuddarain Petang Jakarta. Skripsi PGMI Fakultas Tarbiah dan Ilmu Keguruan:UIN Syarif Hidayatullah Jakarta.

Rusman. 2013. Belajar dan Pembelajaran Berbasis Komputer. Bandung: Alfabeta.

Rusman., Deni, Kurniawan \& Cepi, Riyana. 2012. Pembelajaran Berbasis Teknologi Informasi dan Komunikasi: Mengembangkan Profesionalitas Guru. Jakarta: Rajawali Pres. 
Ability : Journal of Education and Social Analysis

Volume 2, Issue 4, Oktober 2021

Page : 123-134

Samino dan Saring Marsudi. 2012. Layanan Bimbingan Belajar. Solo: Fairus Media.

Sanaky, Hujair AH. 2012. Media Pembelajaran Interaktif- Inovatif. Yogyakarta: Kaukaba Dipantara.

Sudjana, Nana dan Ahmad Rivai. 2013. Media Pengajaran. Bandung: Sinar Baru Algensindo.

Sudjana, Nana . 2012. Penilaian Hasil Proses Belajar Mengajar. Bandung : PT. Remaja Rosdakarya.

Sugiyono. 2016. Metode Penelitian Kuantitatif, Kualitatif, dan RED. Bandung : Alfabeta.

Sukiman. 2011. Pengembangan Media Pembelajaran. Yogyakarta: Pustaka. Insan Madani.

Susanto, Ahmad. 2013. Teori Belajar dan Pembelajaran di Sekolah Dasar. Jakarta: Permada Media Group

Trianto. 2012. Model pembelajara Terpadu. Konsep, Strategi, dan Implementasinya dalam kurikulumTingkatan satuan pendidikan (KTSP). Jakarta: Bumi Aksara.

Wijayanti, Widya dan Stefanus Christian Relmasira. 2019. Pengembangan Media Power Point IPA Untuk Siswa Kelas IV SD Negeri Samirono. Jurnal Penelitian dan Perkembangan Pendidikan. 3(2): 77.

Yudhi Munadi. 2012. Media Pembelajaran: Sebuah Pendekatan Baru. Jakarta: Gaung Press Jakarta. 